\title{
Effects of Polymerization and Spinning Conditions on Mechanical Properties of PAN Precursor Fibers
}

\author{
Qi-feng Qin ${ }^{1}$, Yong-qiang Dai ${ }^{1}$, Kai Yi ${ }^{1}$, Li Zhang ${ }^{1}$, Ryu SeungKon² and Ri-guang Jin ${ }^{1, \wedge}$ \\ ${ }^{1}$ State Key Laboratory of Chemical Resource Engineering, Beijing University of Chemical Technology, Beijing, 100029, China \\ ${ }^{2}$ Dept. of Chemical Engineering, Chungnam National University, Daejeon 305-764, Korea \\ •e-mail: jin.riguang@163.com \\ (Received May 10, 2010; Accepted September 8, 2010)
}

\begin{abstract}
PAN precursor fibers were produced via wet-spinning process, and effects of polymerization and spinning processes, especially the stretching process, were investigated on mechanical properties and micro-morphologies of precursor fibers. An increase in molecular weight, dope solid and densification and a decrease in surface defects were possible by controlling polymerization temperature, the number of heating rollers for densification and the jet stretch ratio, which improved the mechanical properties of precursor fibers. The curves for strength, modulus, tensile power and diameter as a function of stretch ratio can be divided into three stages: steady change area, little change area and sudden change area. With the increase of stretch ratio, the fiber diameter became smaller, the degree of crystallization increased and the structure of precursor fibers became compact and homogeneous, which resulted in the increase of strength, modulus and tensile power of precursor fibers. Empirical relationship between fiber strength and stretch ratio was studied by using the sub-cluster statistical theory. It was successfully predicted when the strengths were $0.8 \mathrm{GPa}$ and $1.0 \mathrm{GPa}$ under a certain technical condition, the corresponding stretch ratio of the fiber were 11.16 and 12.83 respectively.
\end{abstract}

Keywords : Polyacrylonitrile (PAN), Pressured steam stretching, Stretch ratio, Strength, Tensile power

\section{Introduction}

Carbon fiber shows many excellent properties such as high strength, high modulus, low density, thermal stability, and produced from various precursors, including rayon, pitch, and polyacrylonitrile (PAN). The majority of all carbon fibers used today is made from PAN precursor fibers. The performance of the high performance carbon fibers depends on the nature of the precursor fibers [1].

The spinning technique is so complicated that there are many factors affecting the mechanical properties of the final PAN precursor fibers during the spinning process [2,3]. Also $\mathrm{Xu}$ et al. reported the stretching process can increase the orientation degree along the fiber axis and improve the mechanical properties of precursor fibers [2]. However, the relationship between mechanical properties and stretch ratio has not been concretely described in their study.

In general, the stretching process can be conducted in a two-stage procedure: the initial stretching process comprising stretching in bath or a combination of in-air stretching and in-bath stretching, and the second stretching in pressured steam $[4,5]$. The degree of crystallization and orientation of macromolecular can be enhanced further at the latter stage, which plays a more important role in improving the performance of PAN precursor fibers [6-8]. A Japanese patent [9] disclosed T600 precursor fibers prepared by a steam stretching process. In this paper, as for a spinning process, the initial stretch ratio $\left(\lambda_{1}\right)$ in hot water was set as a certain value and re-stretch ratios $\left(\lambda_{2}\right)$ in pressured steam increased gradually to study the effects of the stretch ratio $\left(\lambda_{1} \times \lambda_{1}\right)$ on mechanical properties of PAN precursor fibers.

In addition to the stretch ratio, the other factors affecting the physical properties of precursor fibers include molecular weight, dope solid, jet stretch ratio and the drying densification results, which are closely related to the polymerization and spinning conditions. Therefore, in order to study the influence of the improvement of polymerization and spinning processes on mechanical properties of PAN precursor fibers from these aspects, three different processes were selected to produce PAN precursor fibers in the study. The three different process conditions were given in Table 1 and the other parameters not mentioned were the same as described in Section 2.2. The crystal structure of precursor fibers was examined using X-ray diffractometer (XRD). The single fiber tensile test was used to obtain the mechanical properties of the precursor fibers, and micro-morphologies of the fibers were investigated by scanning electron microscopy (SEM) in the study. Meanwhile, the corresponding stretch ratio of higher-strength PAN precursor fiber was successfully predicted by the sub-cluster statistical theory $[10,11]$ under specific processing conditions for the first time. 
Table 1. Different Process Conditions in Preparation of the PAN Precursors

\begin{tabular}{lcccc}
\hline & $\begin{array}{c}\text { Polymer- } \\
\text { ization } \\
\text { Temp. }\left({ }^{\circ} \mathrm{C}\right)\end{array}$ & $\begin{array}{c}\text { Jet stretch } \\
\text { ratio }\end{array}$ & $\begin{array}{c}\text { Stretch ratio } \\
\text { in hot water } \\
\left(\lambda_{1}\right)\end{array}$ & $\begin{array}{c}\text { Numbers of } \\
\text { densifying } \\
\text { rollers }\end{array}$ \\
\hline Process 1 & 65 & 0.80 & 4.17 & 3 \\
\hline Process 2 & 60 & 0.70 & 5.00 & 3 \\
\hline Process 3 & 55 then 60 & 0.70 & 5.03 & 8 \\
\hline
\end{tabular}

※Process 3: The reaction temperature was controlled at $55^{\circ} \mathrm{C}$ for the former $20 \mathrm{~h}$ and then $60^{\circ} \mathrm{C}$ for the latter $10 \mathrm{~h}$.

\section{Experimental}

\subsection{Materials}

Acrylonitrile (AN, Beijing Chemical Reagents CO.) was freed from inhibitor by atmospheric distillation. Methyl acrylate and itaconic acid (MA, IA, Beijing Second Chemical CO.) were used as the second monomer and the third monomer. Initiator, $\alpha, \alpha$ '-azobisisobutyronitrile (AIBN, Shandong Xueyin Chemical CO.) was purified by recrystallization. Dimethyl sulfoxide (DMSO, Liaoning Panjin Chemical General CO.) was distillated under reduced pressure at $68^{\circ} \mathrm{C}$ to use as solvent and dimethyl formamide (DMF, Beijing Second Chemical Co.) was used as polymer solvent to measure the intrinsic viscosity of the PAN precursor fibers.

\subsection{Polymer synthesis and spinning}

A spinning dope was prepared by radical solution polymerization. Firstly, $1700 \mathrm{~mL}$ DMSO was added into the $3 \mathrm{~L}$ polymeric reactor as solvent. Secondly, according to the desired ratio (AN/MA/IA, 96/3/1,w/w/w), amount of $628 \mathrm{~mL} \mathrm{AN,} 16.5 \mathrm{~mL} \mathrm{MA}$, and $5.27 \mathrm{~g}$ IA were taken into the reactor respectively, and $5.27 \mathrm{~g}$ AIBN was added as an initiator and then polymerized for $30 \mathrm{~h}$ at different temperature from $55^{\circ} \mathrm{C}$ to $65^{\circ} \mathrm{C}$ under pure nitrogen flowing. After demonomerization and deaeration in vacuum for $24 \mathrm{~h}$, the spinning PAN solution was obtained.

The precursor fibers were manufactured by wet-spinning process. The spinning solution went through spinneret plate ( 1000 holes, $0.06 \mathrm{~mm} /$ hole, $\mathrm{L} / \mathrm{D}=1.5$ ) at a certain jet stretch ratio, and then directly turned into the first coagulation bath $\left(70 \% \mathrm{DMSO}, 35^{\circ} \mathrm{C}\right)$, the second coagulation bath $(50 \% \mathrm{DMSO}$, $\left.38^{\circ} \mathrm{C}\right)$ and the third coagulation bath $\left(35 \%\right.$ DMSO, $\left.42^{\circ} \mathrm{C}\right)$ respectively, forming as-spun fibers. The as-spun fiber was stretched in hot water at above $90^{\circ} \mathrm{C}$ firstly, washed in deionized water at $60^{\circ} \mathrm{C}$, and dipped into a water bath containing $1 \%$ silicone oil successively, then densified by drying on heating rollers. In the end, the fibers were stretched with different ratios in the saturated steam at $130^{\circ} \mathrm{C}, 4 \mathrm{~atm}(4 \times 101.325 \mathrm{kPa})$. After the heat-setting process, PAN precursor fibers were obtained.

\subsection{Characterization.}

2.3.1. XRD analysis

A D/max-UltimaIII power X-ray diffractometer (XRD7500, Rigaku, Japan) was used to study XRD patterns of precursor fibers prepared by different process at $40 \mathrm{kV}$ and $40 \mathrm{~mA}$ with $\mathrm{Ni}$-filtered $\mathrm{CuKa}$ radiation $(\lambda=1.54 \AA)$. The scanning speed was $4 \%$ min and scanning speed was $0.02^{\circ}$. The degree of crystallization of PAN precursor ber was measured by $\mathrm{C}=\left(\mathrm{S}_{\mathrm{c}} / \mathrm{S}_{\mathrm{t}}\right) \times 100 \%$, where $\mathrm{S}_{\mathrm{t}}$ is the total peak area, $\mathrm{S}_{\mathrm{c}}$ and is the crystalline peak area. The crystal sizes were calculated by $\mathrm{L}=\mathrm{K} \lambda / \beta \cos \theta$, where $\lambda=1.541 \AA, \mathrm{K}$ is the Scherrer constant ( 0.89 was used), b represents the halfwidth of mid height at $2 \theta=16.9^{\circ}$.

\subsubsection{Observation of micro-morphology}

The surface and cross-section morphologies of PAN precursor fibers were investigated using a field emission-scanning electron microscope (FE-SEM, S4700, Japan) at $25 \mathrm{kV}$ accelerating potential. As a pretreatment, the samples were sputter-coated using Pt (JEOL JFC-1200 fine coater).

\subsubsection{Mechanical properties}

Tensile strength, Yong's modulus and breaking elongation were measured by the electrical single fiber strength machine (YG004E, Ningbo, China). The test were completed according to Chinese National Standard (GB/T 14337-2008) at room temperature of $25^{\circ} \mathrm{C}$ and a controlled relative humidity of $65 \%$. The gauge length was selected as $20 \mathrm{~mm}$ and the drawing speed was set to $10 \mathrm{~mm} / \mathrm{min}$. Twenty single fibers were tested in each sample and the average value can be obtained automatically by the tester.

\subsubsection{Diameter test}

Biologic photomicroscope (U-TV1X, OLYMPUS, Japan) was used for the measurement of diameter of PAN precursor fibers in the experiment. Twenty-six single fibers were selected randomly to be measured in each sample and the average diameter was obtained from 20 data by discarding the top 3 and bottom 3 data.

\section{Results and Discussions}

\subsection{XRD analysis}

As can be seen from the Fig. 1 and Fig. 2, XRD spectrums of PAN precursor fibers showed a sharp strong diffraction at $2 \theta=16.9^{\circ}$ and a weak diffraction at $2 \theta=29.5^{\circ}$, corresponding to the (100) and (110) crystal face respectively, and between the two peaks there was a broad scattering profile, indicating that a irregular molecular structure throughout the macromolecule.

In order to study the effects of the stretch ratio on crystal 


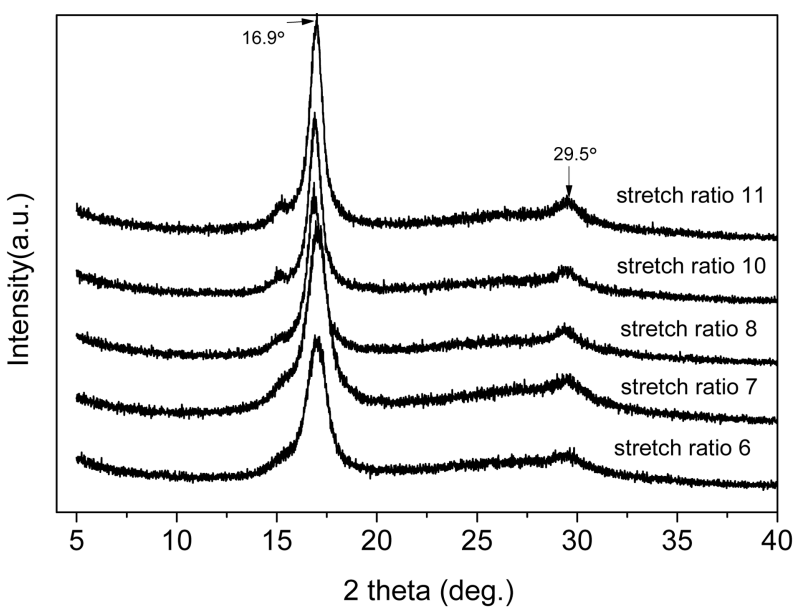

Fig. 1. XRD patterns of precursor fibers prepared by process 2 as a function of the stretch ratio.

structure of PAN precursor fibers, XRD patterns of precursor fibers with different stretch ratio prepared by process 2 were compared as shown in Fig. 1. With increasing stretch ratio, diffraction intensity of (100) crystal face increased and (110) crystal face diffraction became more and more obvious. The degree of crystallization and crystal size were shown in Table 2. With the stretch ratio of 6 times, the degree of crystallization and crystal size of precursor fiber prepared by process 2 were $57.32 \%$ and $52 \AA$, when the stretch ratio was 11 , the degree of crystallization and crystal size increased up to $61.77 \%$ and $79 \AA$, respectively. Degree of crystallization and crystal size increased with the stretch ratio. It was considered that the steam temperature is higher than glass transition temperature of precursor fiber during the steam stretching process, so that the chain segment in amorphous region can move and rearrange, resulting that diffraction
Table 2. The Crystal Parameters of Precursor Fibers Obtained from XRD

\begin{tabular}{cccc}
\hline & $\begin{array}{c}\text { The stretch } \\
\text { ratio }\end{array}$ & $\begin{array}{c}\text { Degree of } \\
\text { Crystallization }(\%)\end{array}$ & $\begin{array}{c}\text { crystal size } \\
(\AA)\end{array}$ \\
\hline \multirow{2}{*}{ Process 1} & 7.96 & 52.45 & 57 \\
\cline { 2 - 4 } & 11.02 & 59.74 & 62 \\
\hline \multirow{3}{*}{ Process 2} & 6.00 & 57.32 & 52 \\
\cline { 2 - 4 } & 7.00 & 59.24 & 50 \\
\cline { 2 - 4 } & 8.00 & 59.84 & 69 \\
\cline { 2 - 4 } & 10.00 & 60.95 & 76 \\
\hline \multirow{2}{*}{ Process 3 } & 11.00 & 61.77 & 79 \\
\cline { 2 - 4 } & 8.45 & 62.04 & 58 \\
\hline
\end{tabular}

intensity of crystal peak increased, amorphous peak decreased, and degree of crystallization of PAN precursor fiber increased.

The XRD patterns of precursor fibers prepared by different process are shown in Fig. 2. When the stretch ratio was approximately 8 , the (100) peak intensity of precursor fiber prepared by processes 3 was the strongest, and Process 1 was the weakest. However, peak intensity of precursor fibers prepared by the three processes were similar at the stretch ratio of approx. 11, indicating the gap of degree of crystallization among them had reduced to some extent under the high-power stretching conditions. Table 2 showed crystallization degree of precursor fiber prepared by process 3 was the highest and precursor prepared by process 1 was the lowest when the stretch ratios were approximately the same.

\subsection{Observation of micro- morphology}

3.2.1. Effects of stretch ratio on surface morphology

No matter by what kind of technology was used in the

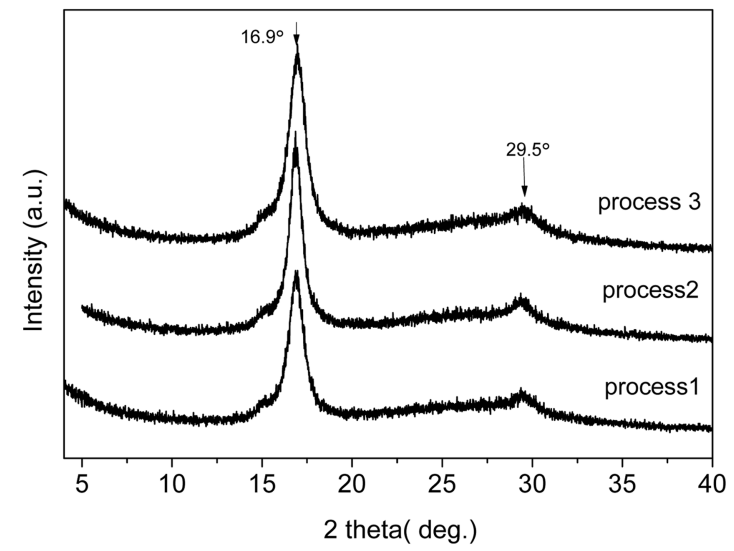

(a)

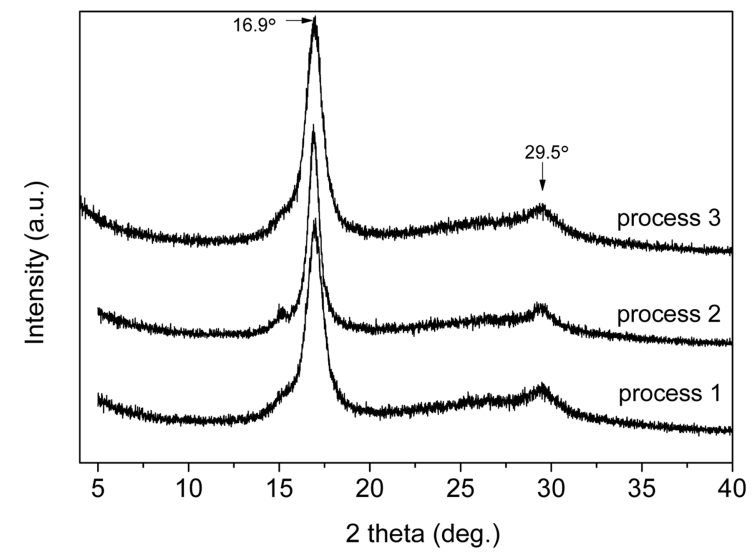

(b)

Fig. 2. XRD patterns of precursor fibers prepared by different process (a) as the stretch ratio of approximately 8 and (b) as the stretch ratio of approximately 11 . 

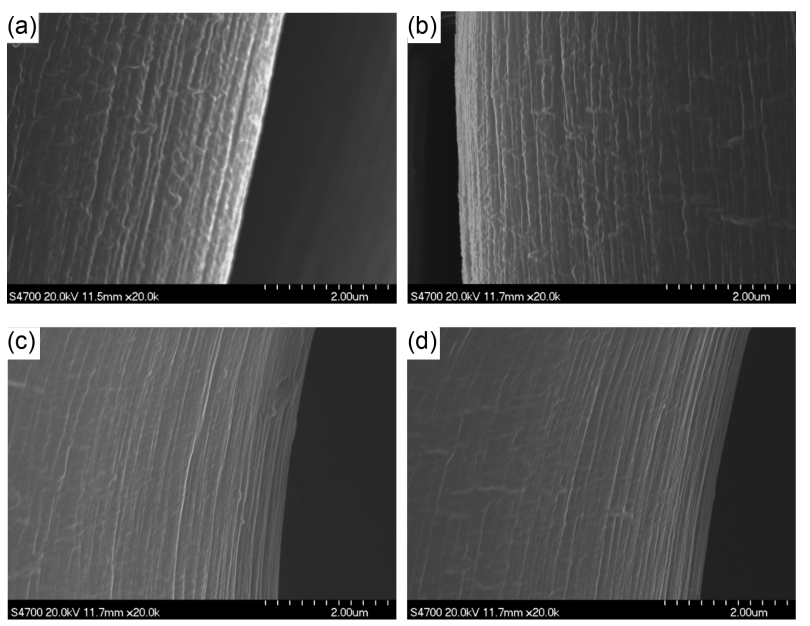

Fig. 3. SEM micrographs of precursor fibers prepared by process 2 at different stretch ratio: stretch ratio of (a) 6 , (b) 7, (c) 8 , and (d) 10.

preparation of the precursor fibers, the surface morphology of precursor fiber was directly related to stretch ratio during the spinning process. Fig. 3 shows SEM micrographs of the precursor fibers produced by process 2 with the stretch ratio equal to $6,7,8$, and 10 , respectively.

In Fig. 3, there were many stripes and grooves on surface of precursor fibers at the low stretching ratio of 6 and 7 , indicating that the surfaces were relatively rough. However, surface defects of the precursor fiber with stretch ratio of 7 times have reduced compared with that of 6 times. As the stretch ratios were up to 8,10 times, the surfaces became smooth and defects decreased significantly. It was considered that crystallization was gradually improved during the stretching process, which is accordant with the results in Table 2, so the stripes and grooves in the surface of precursor fiber decreased with the increase of stretch ratio.

3.2.2. Effects of spinning process on micro-morphology:

To study the influence of the spinning process on micromorphology of PAN precursor fibers, the fibers obtained with the stretch ratio of approximately 11 in different processes have been selected to observe their morphologies using SEM
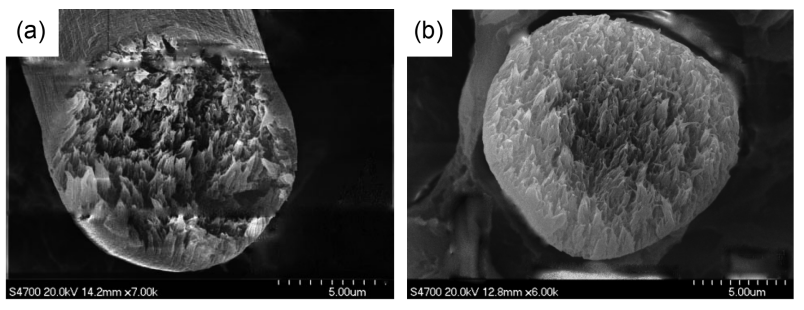

Fig. 5. Cross-section morphologies of fibers: (a) process 1 and (b) process 3 .

as shown in Fig. 4.

As can be seen from Fig. 4, with the stretching ratio of approx. 11 times, there are some fluff and more defects in the surface of the precursor fibers prepared by process 1 and process 2 , and the diameters were relatively large. However, the precursor fiber prepared by process 3 had smoother surface and fewer defects, and the diameter was small.

Fig. 5 shows the cross-section morphologies of the fibers obtained after the drying densification process. The shapes of cross sections of fibers were circle approximately and the fiber prepared by process 3 presented a more homogeneous and compact internal structure in comparison with the fiber prepared by process 1 . The increased hot rollers improved the results of drying densification to make fiber structure denser and diameter smaller.

\subsection{Mechanical properties}

3.3.1. Mechanical properties of PAN precursor fibers prepared by different processes

The mechanical properties of precursor fibers prepared by process 1 were summarized in Table 3. With the high-pull ratio of 12.07, the tensile strength and Yong's modulus were $0.4913 \mathrm{GPa}$ and $4.7526 \mathrm{GPa}$, respectively. When the stretch ratio reached 14 times, the strength increased up to 0.6471 $\mathrm{GPa}$, but the fibers were stretched to broken at the moment. Viscosity-average molecular weight $(\mathrm{M \eta}, 97,000)$ and dope solid $(18.5 \%)$ of the spinning dope were lower, influencing the compactness and mechanical properties of the fiber as has been described and agrees with the Bach's work [12].
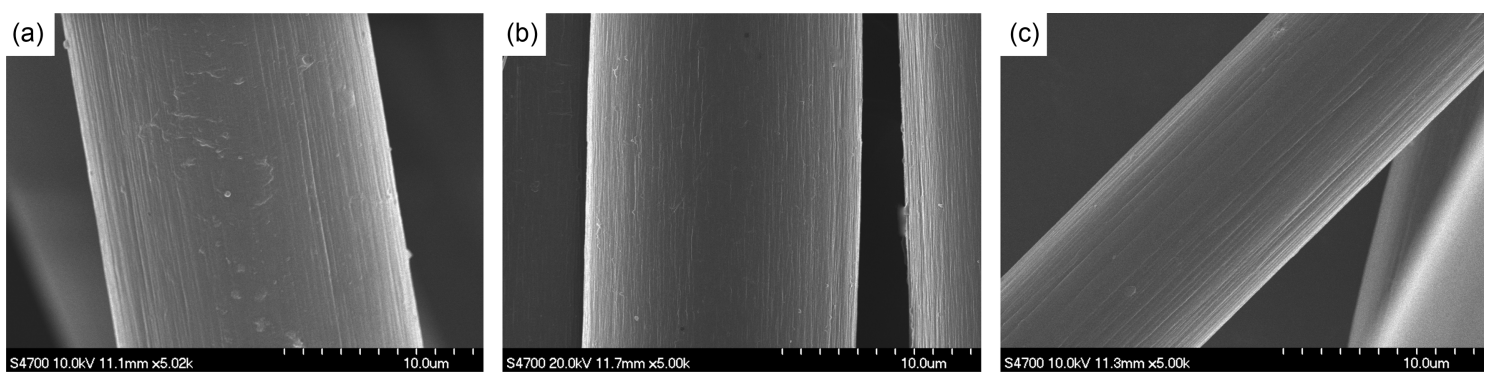

Fig. 4. Surface morphologies of precursor fibers prepared by different spinning process: (a) Process 1, (b) Process 2 and (c) process 3. 
Table 3. Mechanical Properties of Precursor Prepared by Process 1 at Different Stretch Ratios

\begin{tabular}{ccccccc}
\hline $\begin{array}{c}\text { The stretch } \\
\text { ratio }(\lambda)\end{array}$ & $\begin{array}{c}\text { Steam stretch ratio } \\
\left(\lambda_{2}\right)\end{array}$ & $\begin{array}{c}\text { Diameter } \\
(\mu \mathrm{m})\end{array}$ & $\begin{array}{c}\text { Strength } \\
(\mathrm{GPa})\end{array}$ & $\begin{array}{c}\text { Modulus } \\
(\mathrm{GPa})\end{array}$ & $\begin{array}{c}\text { Elongation } \\
(\%)\end{array}$ & $\begin{array}{c}\text { Tensile } \\
\text { power }\end{array}$ \\
\hline 5.00 & 1.20 & 17.74 & $0.3477(6.88)$ & - & $13.4(7.88)$ & 0.04659 \\
6.55 & 1.57 & 15.83 & $0.4368(7.04)$ & 2.7543 & $12.7(6.78)$ & 0.05547 \\
7.96 & 1.91 & 15.12 & $0.4569(6.55)$ & 4.2500 & $12.1(8.01)$ & 0.05528 \\
11.02 & 2.64 & 14.50 & $0.5049(7.33)$ & 4.2543 & $10.9(7.55)$ & 0.05503 \\
12.07 & 2.89 & 13.93 & $0.5113(7.58)$ & 4.7526 & $10.7(7.86)$ & 0.05470 \\
13.49 & 3.13 & 12.84 & $0.5603(6.85)$ & 6.1215 & $9.7(8.22)$ & 0.05434 \\
14.00 & 3.36 & 12.02 & $0.6471(7.25)$ & - & $9.8(8.45)$ & 0.06341 \\
\hline
\end{tabular}

※The $\mathrm{CV} \%$ values are indicated in brackets.

Table 4. Mechanical Properties of Precursor Prepared by Process 2 at Different Stretch Ratios

\begin{tabular}{ccccccc}
\hline $\begin{array}{c}\text { The } \\
\text { stretch ratio }\end{array}$ & $\begin{array}{c}\text { Steam } \\
\text { stretch ratio }\end{array}$ & $\begin{array}{c}\text { Diameter } \\
(\mu \mathrm{m})\end{array}$ & $\begin{array}{c}\text { Strength } \\
(\mathrm{GPa})\end{array}$ & $\begin{array}{c}\text { Modulus } \\
(\mathrm{GPa})\end{array}$ & $\begin{array}{c}\text { Elongation } \\
(\%)\end{array}$ & $\begin{array}{c}\text { Tensile } \\
\text { Power }\end{array}$ \\
\hline 6.00 & 1.20 & 14.28 & $0.4451(7.55)$ & 2.4512 & $13.4(7.88)$ & 0.05964 \\
7.00 & 1.40 & 12.95 & $0.5021(8.45)$ & 3.1432 & $13.1(8.23)$ & 0.06578 \\
8.00 & 1.60 & 12.68 & $0.5392(6.88)$ & 3.9595 & $12.8(7.25)$ & 0.06902 \\
10.00 & 2.00 & 11.70 & $0.5750(7.12)$ & 4.2590 & $13.0(7.56)$ & 0.07475 \\
11.00 & 2.20 & 10.00 & $0.7154(7.33)$ & 5.7561 & $12.1(7.58)$ & 0.08656 \\
Domestic & - & 12.50 & $0.5332(7.23)$ & - & $13.0(6.98)$ & 0.06932 \\
\hline
\end{tabular}

※The $\mathrm{CV} \%$ values are indicated in brackets.

Table 5. Mechanical Properties of Precursor Prepared by Process 3 at Different Stretch Ratios

\begin{tabular}{ccccccc}
\hline $\begin{array}{c}\text { The } \\
\text { stretch ratio }\end{array}$ & $\begin{array}{c}\text { Steam } \\
\text { stretch ratio }\end{array}$ & $\begin{array}{c}\text { Diameter } \\
(\mu \mathrm{m})\end{array}$ & $\begin{array}{c}\text { Strength } \\
(\mathrm{GPa})\end{array}$ & $\begin{array}{c}\text { Modulus } \\
(\mathrm{GPa})\end{array}$ & $\begin{array}{c}\text { Elongation } \\
(\%)\end{array}$ & $\begin{array}{c}\text { Tensile } \\
\text { Power }\end{array}$ \\
\hline 5.03 & 1.00 & 17.75 & $0.3811(6.86)$ & 2.4694 & $16.85(6.59)$ & 0.06421 \\
6.05 & 1.20 & 12.68 & $0.6875(7.12)$ & 3.8611 & $15.80(6.74)$ & 0.1086 \\
8.45 & 1.68 & 10.15 & $1.1190(6.54)$ & 5.5447 & $15.40(6.33)$ & 0.1723 \\
10.97 & 2.01 & 9.68 & $1.1864(6.77)$ & 5.5314 & $15.30(6.48)$ & 0.1815 \\
11.72 & 2.33 & 9.14 & $1.3949(6.98)$ & 6.3457 & $14.50(6.36)$ & 0.2023 \\
\hline
\end{tabular}

※The $\mathrm{CV} \%$ values are indicated in brackets.

Moreover, the filaments spun from spinneret were stretched excessively with the jet stretch ratio of 0.80 . The jet stretch ratio cannot be too high; otherwise the failure in the filaments will occur. As shown in Fig. 4(a), the coagulated epidermal structure was damaged and much fluff and many defects emerged in the surface of the precursor fiber during the stretching process. Therefore, to improve physical properties of the precursor fiber, molecular weight and dope solid should be increased while the jet stretch ratio should be decreased.

As can be seen from Table 4, the precursor fibers prepared by process 2 were superior to process 1 in mechanical properties. For example, the strength of the precursor fiber was $0.7154 \mathrm{GPa}$ and the breaking elongation rate was $12.1 \%$ at the stretch ratio of 11 , both of which were relatively larger in comparison with the former precursor fiber and has reached the level of domestic precursor fiber. The dope solid $(19.8 \%)$ and viscosity-average molecular weight $(\mathrm{M \eta}, 127,000)$ both increased by decreasing the polymerization temperature to $60^{\circ} \mathrm{C}$. The defects of as-spun fiber caused by barus effect reduced with the decrease of jet stretch ratio. As shown in Fig. 4(b), the precursor fibers prepared by process 2 had smoother surface under the high-stretching conditions. $\mathrm{Ji}$ [13] reported the optimal parameter of jet stretch ratio was 0.70 , which is accordant with our experimental results.

Table 5 shows mechanical properties of precursor fibers prepared by process 3.The precursor fibers exhibited the best mechanical properties. With the stretch ratio of 8.45 times, the fiber strength and modulus had reached $1 \mathrm{GPa}$ and $5.5314 \mathrm{GPa}$ respectively, and the breaking elongation rate was up to $15.4 \%$. With increasing stretch ratio, the fiber strength increased up to $1.39 \mathrm{GPa}$. It is rare that similar products have reached such a high strength in the reported literatures. Controlling the polymerization temperature by stages not only ensured the higher molecular weight $(\mathrm{M \eta}$, $169,000)$, but also made dope solid up to $21 \%$. An increase 


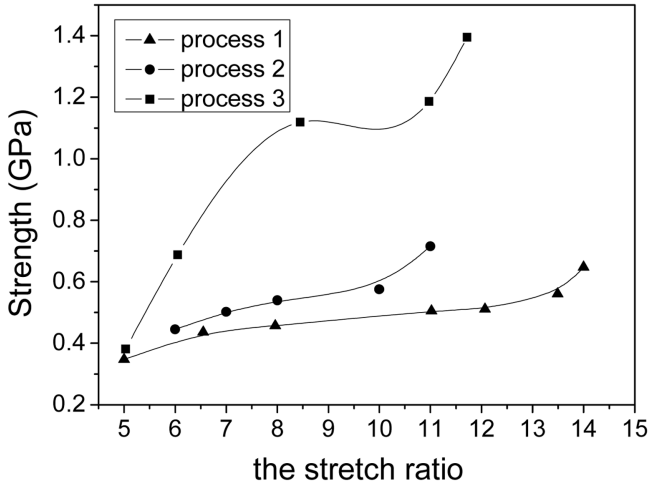

(a)

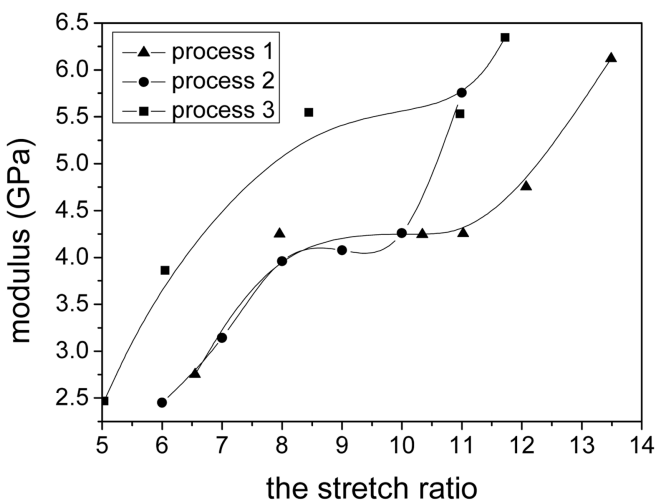

(b)

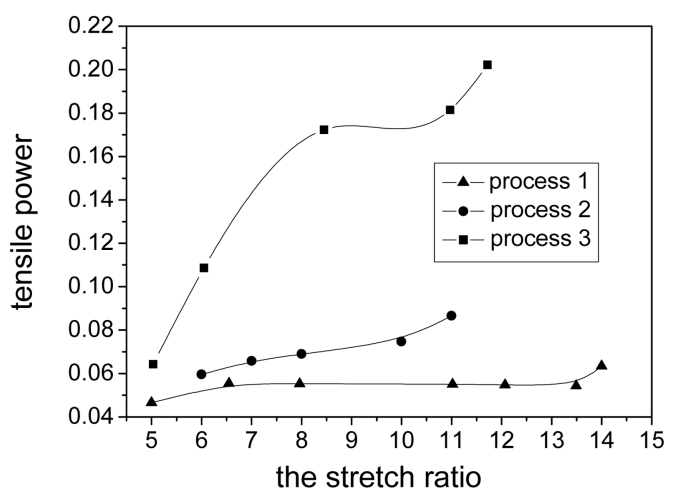

(c)

Fig. 6. The effects of the stretch ratio on mechanical properties: (a) strength, (b) modulus and (c) tensile power.

in the dope solid improved the homogeneity of the fiber structure and slightly increased the density of PAN fibers [3]. Besides, increased hot rollers of drying collapse further ensured the drying time and results of the densification. The drying densification process can improve the degree of crystallization and orientation of the fiber while reducing the voids significantly to make the fiber have a more compact structure [8]. In Table 2, the degree of crystallization of precursor fiber prepared by process 3 was the highest under the same stretch conditions. To some extent, the higher dope solid and molecular weight and the degree of crystallization, the better performance of PAN precursor fibers is.

\subsubsection{Effects of stretch ratio on mechanical properties}

First, define a new performance parameter of tensile power(S) $: S=$ Strength $\times$ Elongation, being the product of tensile strength and fracture elongation of the fiber. Tensile power reflects tensile capacity and the overall performance of the fiber directly from the overall perspective of strength and elongation. For example, if the precursor fiber is lower in the strength but higher in the tensile power, which indicates that fracture elongation is larger and the precursor fiber can be stretched further to improve its' strength [2], so the tensile power is an important index for measuring mechanical properties of the fiber.

Based on the experimental results above, the following three graphs were plotted in Fig. 6. Regardless of which spinning process we used, the initial properties of the precursor fibers at a low stretch ratio were approximately the same, but the gap of mechanical properties widened with the increase of stretch ratio. It can be seen from Fig. 6, the strength, Young's modulus and tensile power increased with the stretch ratio in general and the change tendency of tensile power with the increased stretch ratio was similar to that of strength. Moreover, the curves in the three graphs all can be divided into three stages as a whole: I, the area of performance increasing steadily with stretch ratio; II, the platform area of little change in performance with stretch ratio; III, the area of performance increasing suddenly with stretch ratio. However, the precursor fibers prepared by process 3 exhibited the highest strength, modulus and tensile power under the same stretch conditions, it mainly caused by the increase of molecular weight, dope solid and densification for the improvement of polymerization and spinning process. From Table 2 and Fig. 6, the degree of crystallization increased with the stretch ratio and the precursor fibers with 


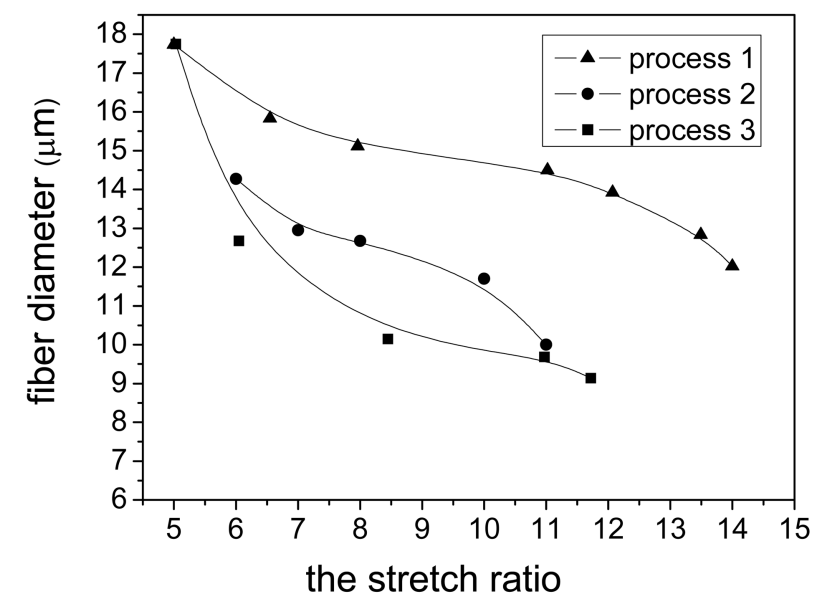

Fig. 7. The effects of the stretch ratio on precursor diameter in different processes.

higher degree of crystallization had a higher strength, modulus and tensile power under a certain process condition.

\subsubsection{Effects of stretch ratio on fiber diameter}

Fig. 7 shows the relationship between fiber diameter and stretch ratio in different stretching process. Diameter of PAN precursor fiber decreased with the increase of stretch ratio. The diameter of the precursor fiber prepared by process 1 was the largest and precursor fiber prepared by process 3 was the lowest, and the curves can be divided into three stages:I, the area of diameter declined steadily with stretch ratio; II, the area of diameter declined slowly with stretch ratio; III, the area of diameter declined suddenly with stretch ratio. As shown in Figs. 6 and 7: the smaller the diameter of fiber, the higher strength, modulus and tensile power of precursor fiber. The diameter decreased and degree of crystallization increased with the stretch ratio, which reduced defects and strength dispersion of PAN precursor fiber to improve the performance of the overall fibers. The experimental results provided a certain theoretical basic for the preparation of ultrafine high-strength and high-modulus carbon fiber.

\subsection{Theoretical study on the relationship between strength and stretch ratio}

Among the mechanical properties, the strength of the precursor fiber is the most important. From Fig. 7(a), the curves of strength with the increased stretch ratio can be divided into three stages, and the third stage during the stretching process played a decisive role in improving the strength of precursor fiber better. If we can predict the corresponding stretch ratio of higher-strength PAN precursor using available data under a certain process condition, it will have an important practical significance for the progress of our research.
The curve of process 2 in Fig. 7(a) was selected for example in the study, if the strength of precursor fiber prepared under the process 2 conditions raises to $0.8 \mathrm{GPa}$ and $1 \mathrm{GPa}$, how much the stretch ratio should increase? The problem has not been solved in the process of preparing PAN precursor fibers, because there hasn't a model equation. However, the problem will be solved by using the subcluster statistical equation $[10,11]$ in this paper:

where $\sim 23$ : refers to macromolecular chain with low stretch ratio;

_ refers to macromolecular chain with high stretch ratio.

According to JRG sub-cluster statistical theory, the two typical macromolecular chains compete for each other in the stretching process and there mainly exist the following four competing processes.

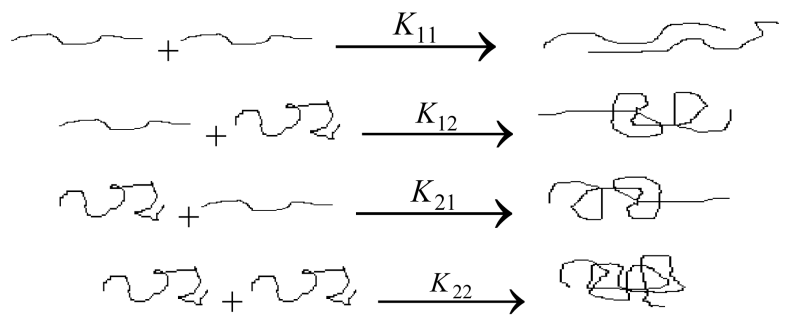

According to sub-cluster statistical theory, we can get the follow equation (1):

$$
\frac{\sigma-\sigma_{\min }}{\sigma_{\max }-\sigma}=\frac{1+\frac{k_{11}}{k_{12}} \cdot \frac{\lambda-\lambda_{\min }}{\lambda_{\max }-\lambda}}{1+\frac{k_{22}}{k_{21}} \cdot \frac{\lambda_{\max }-\lambda}{\lambda-\lambda_{\min }}}
$$

where $\mathrm{K}$ : proportional coefficient and usually take $\mathrm{K}=1$,

$\sigma$ : strength of precursor fiber(GPa),

$\sigma_{\min }:$ minimum strength of precursor fiber in the experiment (GPa),

$\sigma_{\max }$ : maximum strength of precursor fiber in the experiment (GPa),

$\lambda:$ stretch ratio,

$\lambda_{\text {min }}:$ minimum of stretch ratio in the experiment,

$\lambda_{\max }:$ maximum of stretch ratio in the experiment.

Firstly, strength $(\sigma)$ and the stretch $\operatorname{ratio}(\lambda)$ were normalized according to the following equation:

$$
\begin{aligned}
& \frac{\sigma-\sigma_{\min }}{\sigma_{\max }-\sigma_{\min }}=y, \frac{\lambda-\lambda_{\min }}{\lambda_{\max }-\lambda_{\min }}=x . \\
& Y=\frac{\mathrm{y}}{1-y}, X=\frac{\mathrm{x}}{1-x}
\end{aligned}
$$

Therefore, from (1) and (2):

$$
Y=\frac{1+R_{1} \cdot X}{1+R_{2} \cdot \frac{1}{X}}, R_{1}=\frac{k_{11}}{k_{12}}, R_{2}=\frac{k_{22}}{k_{21}}
$$




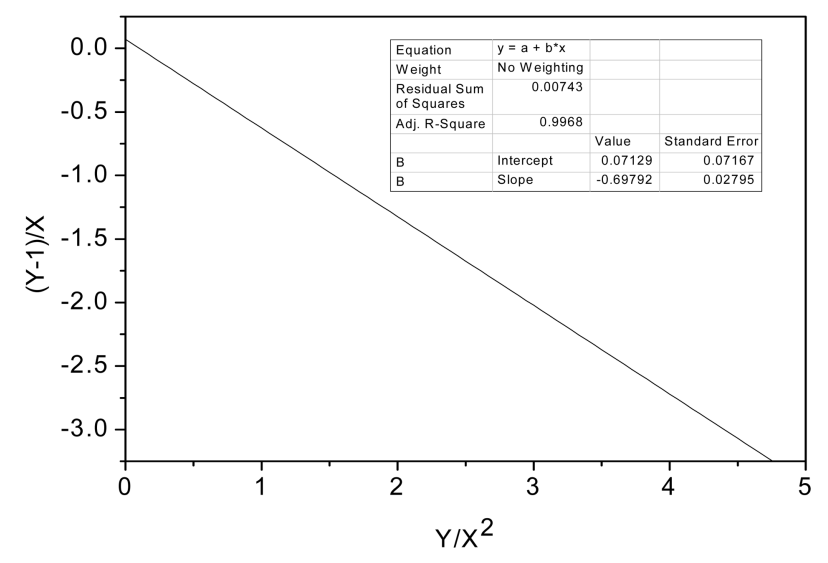

Fig. 8. The regression graph of $(\mathrm{Y}-1) / \mathrm{X}$ and $\mathrm{Y} / \mathrm{X}^{2}$.

The formula (3) can be changed as the following form:

$$
\frac{Y-1}{X}+R_{2} \frac{Y}{X^{2}}=R_{1}
$$

According to the existing data in Table 4 and formula (2), the values of $\mathrm{x}, \mathrm{y}, \mathrm{X}$, and $\mathrm{Y}$ can be calculated respectively. The drawing was made with $\frac{Y-1}{X}$ as ordinate and $\frac{Y}{X^{2}}$ as abscissas by computer as shown in Fig. 8 . And then the regression line can be obtained with a slope of $-\mathrm{R}_{2}$ and the intercept value of $\mathrm{R}_{1}$. By using the computer linear regression, the values of $\mathrm{R}_{1}$ and $R_{2}$ were 0.07129 and 0.6979 , respectively.

The corresponding stretch ratios of $0.8 \mathrm{GPa}$ and $1 \mathrm{GPa}$ were determined after substituting $\mathrm{R}_{1}$ and $\mathrm{R}_{2}$ into equations (1) inversely. If the precursor is prepared by process 2 , when fiber strengths are $0.8 \mathrm{GPa}$ and $1.0 \mathrm{GPa}$, the corresponding stretch ratios of the fiber are 11.16 and 12.83 respectively by sub-cluster statistical theory $[10,11]$.

\section{Conclusions}

The tensile strength, Yong's modulus and tensile power of wet-spun PAN precursor fiber increased with the increase of molecular weight, dope solid, and densification of precursor.
Also, the mechanical properties were closely related to the polymerization and spinning process. The curves of strength, modulus, tensile power and diameter as a function of stretch ratio in all the spinning processes can be divided into three stages: steady change area, little change area and sudden change area. With the increase of stretch ratio, the fiber diameter became smaller, the degree of crystallization increased and the structure of precursor fibers became compact and homogeneous, which resulted in the increase of strength, modulus and tensile power of PAN precursor fibers. When the strengths of precursor fiber were $0.8 \mathrm{GPa}$ and 1.0 $\mathrm{GPa}$, the corresponding stretch ratio of the fiber can be successfully predicted to 11.16 and 12.83 , respectively, by using sub-cluster statistical theory.

\section{References}

[1] Bahl, O. P.; Mathur, R. B.; Kundera, K. D. Fiber Sci. Technol. 1981, 15, 147.

[2] Xu, Q. A.; Xu, L. H.; Wu, S. Z. Polym, Adv, Technol. 2005, 16,642 .

[3] Keshav, V. D. Synthetic Fibers 1994, 10, 37.

[4] Mikolajczyk, T.; Szparaga, G.; Bogun, M.; Fraczek-Szczypta, A.; Blazewicz, S. J. Applied Polymer Science 2009, 115,3628 .

[5] Mitsubishi Rayon Co., Ltd. EP1130140A1, 2001-05-09.

[6] Davidson, J. A.; Jung, H. T.; Hudson, S. D. Polymer 2000, 41, 3357.

[7] Gupta, B. S.; Mogahzy, Y. E. J. Applied Polymer Science 1989, 38, 899.

[8] Zhang, W. X.. Hi-Tech Fiber \& Application 2001, 26, 12.

[9] Japan Toray Co., Ltd. JP58-214520,1983-12-13.

[10] Jin, R. G. Korea Xuanwen Media Market Press, 1994.

[11] Jin, R. G. Heilongjiang Science and Technology Press, 1985.

[12] Bach, H. C.; Knorr, R. S.; Mark, H. F.; Bikales, N. M.; Overberger, C. G; Menges, G; Kroschwitz, J. I. "Encyclopedia of polymer science and technology", Vol. 1, Wiley, New York, 1985, 339.

[13] Ji, B. H.; Wang, C.G.; Wang, Y. X. J. of Appl. Polym. Sci. 2007, 103, 3348 . 